\title{
Diferenças na atividade de monitoramento de informações do ambiente externo em pequenas e médias empresas: a influência do porte e da idade
}

\author{
Éverton Luís Pellizzaro de Lorenzi Cancellier
}

Doutor em Administração pela Faculdade de Economia, Administração e Contabilidade da Universidade de São Paulo. Professor do Departamento de Administração Empresarial e do Mestrado Profissional em Administração da Universidade do Estado de Santa Catarina.

Anete Alberton

Doutora em Engenharia de Produção pela Universidade Federal de Santa Catarina (UFSC). Professora do Doutorado em Administração e Turismo, do Mestrado em Administração, do Mestrado em Turismo e Hotelaria e do curso de graduação em Administração da Universidade do Vale do Itajaí.

\section{Anielson Barbosa}

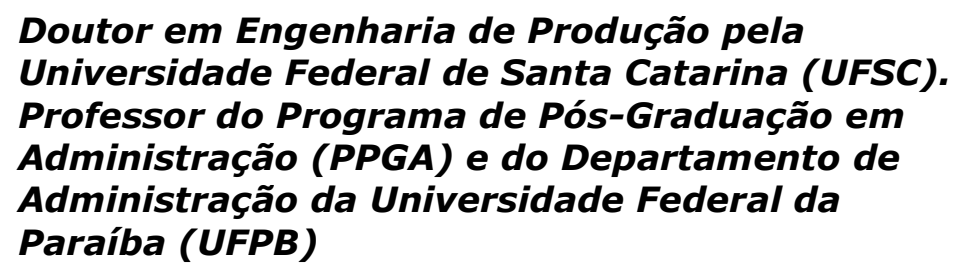

Este trabalho objetiva estudar o monitoramento de informações estratégicas do ambiente externo em pequenas empresas, e sua relevância situa-se no fato de que os estudos sobre monitoramento nas pequenas empresas, ainda são incipientes no Brasil. É um estudo do tipo levantamento ou survey, com aplicação de questionário aplicado aos dirigentes de 188 empresas. Na análise dos dados, utilizou-se a técnica de análise de variância das médias dos grupos. Os resultados indicaram que as empresas privilegiam o monitoramento de alguns aspectos do ambiente e foram encontradas maiores diferenças na frequência de monitoramento em relação à idade das empresas do que em relação ao porte. 


\section{Palavras-Chave: Monitoramento; Informação Estratégica; Ambiente Externo; Pequenas e Médias Empresas. \\ Differences in the Information Activity Monitoring from External Environment in Small and Medium Businesses: the influence of size and age}

This paper aims to study the scanning of strategic information from the external environment in small business and the relevance of this lies in the fact that the studies about scanning in small companies are still incipient in Brazil. It's a survey study, with application of questionnaire to executives of 188 companies. In data analysis, we used the technique of analysis of variance of group means. The results indicated that small businesses prefer to scan some aspects from environment and were found major differences in the frequency of scanning in relation to the age of firms than in terms of size.

Keywords: Scanning; Strategic information; External Environment; Small and Medium Enterprises.

Recebido em 04.02.2010 Aceito em 01.06.2011

\section{Introdução}

O monitoramento, entendido como a atividade das organizações de adquirir informações sobre o ambiente (GHOSHAL, 1988; CHOO, 1999), é a atividade que permite aos dirigentes formular e conhecer o contexto em que a empresa está inserida. Aguilar (1967), em seu trabalho pioneiro, define o monitoramento como a forma pela qual os dirigentes obtêm informações relevantes sobre eventos que ocorrem fora da empresa, de maneira a guiar futuros cursos de ação.

Uma das principais vantagens de adotar práticas de monitoramento ambiental reside na possibilidade de conhecer oportunidades e ameaças, que influem no desempenho e na sobrevivência organizacional, capacitando a empresa a formular estratégias competitivas congruentes com as condições ambientais enfrentadas (BEAL, 2000).

O monitoramento ambiental pode ser considerado como o primeiro passo no processo de alcançar um adequado ajuste da estratégia da organização com o ambiente (BEAL, 2000). Uma menor atividade de monitoramento pode colocar as pequenas empresas em uma 
desvantagem de informação e, consequentemente, em desvantagem competitiva em relação aos competidores, especialmente as empresas maiores (STRANDHOLM; KUMAR, 2003).

O monitoramento ambiental merece estudos específicos voltados para a compreensão das práticas realizadas na pequena empresa, uma vez que sua realidade é bastante diversa da encontrada nas grandes organizações. Dentre as principais diferenças entre pequenas e grandes empresas, que justificam a escolha do tema, pode-se citar:

a) pequenas empresas possuem recursos limitados e não dispõem do capital que muitas técnicas de monitoramento exigem para a coleta e análise de informações (GOLDE, 1964; LANG et al., 1997);

b) a responsabilidade pela tomada de decisão, tanto estratégica como operacional, está concentrada em um ou poucos indivíduos, ao contrário da divisão especializada de tarefas entre os executivos das grandes empresas (HAMBRICK, 1981); e

c) as pequenas empresas não costumam apresentar sistemas de informações gerenciais sofisticados de suporte para a tomada de decisão (KAGAN et al., 1990).

Devido às diferenças e ao fato de o monitoramento estar associado com o desempenho, tanto em grandes como em pequenas organizações (STRANDHOLM; KUMAR, 2003), mostra-se relevante estudar as práticas de monitoramento de informações no âmbito das pequenas e médias empresas.

Estudar diferenças no monitoramento, em relação ao porte de empresas, justifica-se na medida em que as organizações crescem e diferenças nos processos de gestão podem surgir. Com o crescimento, sistemas mais formais são desenvolvidos, pelos quais a informação passa e vai sendo filtrada, tornando-se, também, mais formalizada e sistemática do que nos menores negócios, o que contribui para o enriquecimento das informações disponíveis aos dirigentes (SMELTZER et al., 1988). Nas empresas menores, os canais de decisão são mais curtos e as estruturas são mais simples, pois os grupos são pequenos ao redor do dono, permitindo que se perceba oportunidades e que ações sejam implantadas com rapidez (PEARCE II et al., 1982; CHEN; HAMBRICK, 1995). As variações nas atividades de monitoramento, em empresas de diferentes portes, encontra evidências no estudo de Johnson e Kuehn (1987), que verificaram diferenças importantes no monitoramento realizado por pequenas e grandes empresas, e no estudo de Groom e David (2001), em que o fator tamanho foi significativo para diferenças de porte, mesmo em uma amostra de pequenas empresas.

O estudo das diferenças no monitoramento em relação à idade justifica-se na medida em o tempo é um fator relevante para a 
aprendizagem e a sobrevivência organizacional. Para Brusch (1992), a pesquisa na área de empreendedorismo mostra que a falta de informações sobre o mercado de atuação é um dos mais sérios problemas para a criação de novos empreendimentos e, ainda, estudos no Brasil, acerca das causas da alta taxa de mortalidade de novos negócios, apontam para a falta de informações do ambiente externo, em especial dados de mercado e clientes (SEBRAE, 2004).

Assim, o exposto acima norteou a elaboração das seguintes perguntas de pesquisa: Quais aspectos do ambiente externo são monitorados com maior frequência pelas pequenas e médias empresas? As empresas estão satisfeitas ou desejam mais informações sobre esses aspectos? Quais são as diferenças na frequência de monitoramento de aspectos ambientais com base no porte das pequenas e médias empresas? Quais são as diferenças na frequência de monitoramento de aspectos ambientais, com base na idade das pequenas e médias empresas? Desta forma, a principal contribuição deste estudo, consiste em identificar as práticas de monitoramento em pequenas e médias empresas e verificar a existência de diferenças no monitoramento com base no porte e idade.

\section{Fundamentação teórica}

Subramanian, Fernandes e Harper (1993) conceituam monitoramento ambiental como o processo pelo qual uma organização coleta informações do ambiente que serão posteriormente utilizadas no seu processo de administração estratégica. Os autores defendem que implantar um sistema de monitoramento efetivo exige não apenas estabelecer os procedimentos de coleta de informações relevantes e tempestivas, mas, também, deve envolver a disseminação destas informações para os devidos usuários. Este é um processo basicamente mental, uma vez que se trata de obter informações relevantes e oportunas, exigindo frequentes julgamentos, em várias etapas do processo de monitoramento. Considerando-se que o valor da utilidade de uma dada informação só pode ser definido após seu real uso na tomada de decisão, o processo de monitoramento é concluído quando há recebimento do feedback das ações tomadas com o auxílio das informações fornecidas pelo processo de monitoramento.

O ambiente, definido como tudo aquilo que está além das fronteiras da organização (HALL, 1984), possui inúmeros aspectos que podem ser contemplados nas atividades de monitoramento. Estes aspectos podem ser classificados na proposição clássica de Dill (1958) para o ambiente de tarefa, composto por entidades ou objetos identificáveis e externos à empresa. O ambiente de tarefa é mais próximo e específico e contém os elementos e fatores de influência imediata para os objetivos organizacionais, sendo composto por aspectos como clientes, fornecedores, competidores e organismos regulatórios. O ambiente geral possui limites que correspondem a toda a sociedade e que influenciam 
indiretamente as organizações, sendo composto pelas condições econômicas, sociais, culturais e legais gerais das sociedades.

Os estudos em monitoramento ambiental procuram identificar os padrões de busca e análise de informações por parte das organizações. Verificam-se, especialmente, os tipos de informação mais pesquisados, sejam do macroambiente ou do ambiente de tarefa, a frequência de busca destas informações e as fontes utilizadas para obtê-las. Nessa linha, estão os estudos de Smeltzer et al. (1988), Fann e Smeltzer (1989), Pineda et al. (1998) e Analoui e Karami (2002).

O estudo de Smeltzer et al. (1988) investigou práticas de monitoramento ambiental de pequenas empresas e identificou a frequência de monitoramento e as fontes de informações mais usadas por organizações de pequeno porte desprovidas de staff executivo e dirigidas por seus próprios donos. Os setores do ambiente considerados mais importantes e mais monitorados foram o mercado de atuação e as condições da economia. Embora o mercado de atuação tenha recebido destaque, os competidores não foram vistos como fontes importantes de informações e os dirigentes entrevistados tinham poucas coisas a falar sobre eles.

Os competidores também receberam menor atenção e esforço de monitoramento no estudo Fann e Smeltzer (1989), que investigou o uso que pequenas empresas fazem de informações sobre concorrentes, no planejamento de curto e de longo prazo. De forma geral, a pesquisa mostrou que as pequenas empresas não valorizam informações sobre a concorrência e consideram que se seu produto é bom, ele será vendido, fazendo pouca diferença a postura dos competidores. O pouco apreço pelo papel dos concorrentes ocorreu independentemente do porte, receita, idade ou setor de atuação das empresas pesquisadas.

A desatenção para com competidores também foi detectada em estudos realizados no Brasil. Fidelis e Cendon (2002), em estudo realizado com pequenas e médias indústrias do setor metal mecânico do Vale do Aço, em Minas Gerais, identificaram que grande parte das empresas não procuram informações sobre concorrentes ou o fazem de forma esporádica, enquanto Almeida (1997) identificou que informações sobre os concorrentes estão entre as de menor importância para uma amostra de pequenas empresas paranaenses.

Procurando identificar os fatores que levam à escolha de certas fontes de informação na pequena empresa, Pineda et al. (1998) constataram que a intensidade da busca de informações varia conforme a área de decisão. Na sua pesquisa, identificaram que algumas áreas de decisão são mais monitoradas que outras: linha de produtos e qualidade dos produtos são mais pesquisadas do que finanças e escolha de sistemas computacionais. As áreas de decisão mais monitoradas são justamente aquelas consideradas mais importantes e, nas quais, os dirigentes julgamse mais eficazes em lidar com elas.

No estudo de Analoui e Karami (2002) com pequenas e médias empresas da indústria eletro-eletrônica inglesa, 0 aspecto do 
macroambiente, considerado de maior impacto, foram as mudanças tecnológicas seguidas das tendências econômicas e os aspectos do ambiente de tarefa de maior impacto foram o poder de barganha dos clientes, seguido pela rivalidade das empresas do setor.

Dentre os que abordam as diferenças de monitoramento, com base no porte ou idade, destacam-se os estudos de Johnson e Kuehn (1987), Groom e David (2001), Strandholm e Kumar (2003), Barbosa (2006) e de Mohan-Neiil (1995), sendo que este último verificou a influência tanto do porte quanto da idade para a busca de informações.

Em relação à influência do porte nas atividades de monitoramento, Johnson e Kuehn (1987) compararam o processo de aquisição de informação e o valor a elas atribuído pelos dirigentes de pequenas empresas com uma amostra de grandes empresas. A pesquisa de Johnson e Kuehn (1987) apresenta diferenças importantes no monitoramento realizado por pequenas e grandes empresas. Os dirigentes das pequenas empresas pesquisadas mostraram-se mais envolvidos e gastaram mais tempo com informações externas (aproximadamente 1/4 do seu tempo) do que seus colegas nas grandes organizações (aproximadamente 1/6 do seu tempo). Também utilizaram mais tempo para monitorar o mercado de atuação (vendas, competidores, consumidores) e 0 potencial de crescimento do que as grandes empresas, que utilizam mais tempo para monitorar tecnologia e questões governamentais. Questões econômicas não mostraram diferenças de tempo significativas entre as pequenas e grandes empresas da amostra.

O fator tamanho mostrou influência nas práticas de monitoramento do estudo de Groom e David (2001). Os autores identificaram que as pequenas empresas, com mais de 10 empregados, privilegiam fontes internas, enquanto as com até 10 empregados, privilegiam fontes externas, indicando que, mesmo entre as pequenas empresas, as de menor porte parecem usar mais fontes externas, enquanto as maiores usam mais fontes internas. Outro achado importante foi que a maioria das pequenas organizações não se engajam ativamente na coleta e análise de inteligência sobre competidores.

Em estudo semelhante, Strandholm e Kumar (2003) examinaram diferenças nas atividades de monitoramento do ambiente entre pequenos e grandes hospitais. Usando como critério número de leitos e a mediana de 200 leitos da amostra para dividir em pequenas e grandes organizações, encontraram evidências de que os dois grupos não eram iguais. A análise de variância mostrou diferenças estatísticas entre as médias das unidades consideradas pequenas, que foi levemente menor do que as médias das grandes unidades da amostra, tanto em relação ao escopo quanto em relação à frequência do monitoramento. Assim, os resultados indicam que as pequenas empresas monitoram um número menor de aspectos do ambiente, a uma taxa de frequência também menor do que as grandes empresas.

No Brasil, Barbosa (2006) encontrou diferenças no uso de fontes de informação para o monitoramento do ambiente entre empresas de 
pequeno e grande porte. Os profissionais das grandes empresas, de seu estudo, fizeram maior uso de fontes escritas externas, escritas internas e pessoais internas, reforçando o efeito tamanho das empresas nas práticas de monitoramento.

Mohan-Neiil (1995) agregou a influência da idade ao fator tamanho, na busca de informações do ambiente externo. Seus resultados encontraram de pequenas a moderadas correlações positivas entre idade e a frequência de monitoramento para os 3 aspectos do macroambiente investigados (tendências demográficas, tendências da população e tendências socioculturais) e para 5 dos 9 aspectos do ambiente de tarefa investigados (crescimento de mercado, segmentos de mercado, estratégia de concorrentes, vendas dos concorrentes, serviços dos concorrentes e novos entrantes). Em relação ao porte, em termos de número de funcionários e receita de vendas, foram encontradas correlações positivas pequenas para os aspectos tendências demográficas e tendências da população do macroambiente e para os aspectos crescimento de mercado e segmentos de mercado do ambiente de tarefa. Assim, nos resultados, a idade mostrou-se uma variável mais significativa para diferenças no monitoramento do que o porte.

\section{Metodologia}

Esta pesquisa caracterizou-se por ser um estudo descritivo do tipo levantamento ou survey com corte transversal. A pesquisa do tipo levantamento ou survey é aquela em que o objetivo principal é examinar a existência de padrões e relacionamentos entre determinadas variáveis, obtendo dados por meio de entrevistas ou questionários (BRYMAN, 1989). A informação é coletada em um número determinado de variáveis e infere-se o grau de causalidade e relação entre elas. O corte transversal é caracterizado pelo fato de se pesquisar as práticas de monitoramento ambiental presente nas empresas no momento da realização pesquisa, sem investigação das práticas passadas ou sua evolução no tempo, o que caraterizaria um corte longitudinal.

A população alvo da pesquisa foi composta por empresas de pequeno e médio porte, localizadas na região da grande Florianópolis, com pelo menos 1 (um) ano de atividade ininterrupta. Para a classificação das empresas, foi utilizado o critério número de empregados. O tempo mínimo de existência foi considerado importante, por excluir a participação de empresas recém criadas e ainda em fase de estruturação e entrada em seus respectivos mercados. A listagem da população foi obtida mediante fornecimento do cadastro de empresas da Federação das Indústrias do Estado de Santa Catarina (FIESC) e das Associações Comerciais e Industriais dos municípios abrangidos na pesquisa, perfazendo uma amostra de 188 empresas.

A coleta de dados foi realizada por meio da aplicação de questionários autoadministrados, após contato prévio com a empresa. Este tipo de questionário é aquele estruturado de forma a que o 
respondente possa preencher o conjunto de questões por si mesmo, sem o auxílio ou intervenção do pesquisador. Mesmo assim, optou-se pela visita do pesquisador às unidades da amostra, para preenchimento do questionário, evitando o não retorno de instrumentos, quando autoadministrados. Precedeu-se a coleta a realização de pré-testes com 4 unidades da população previamente escolhidas, de forma a assegurar a eficaz estruturação das questões e assegurar a compreensão dos respondentes sobre o conteúdo do questionário.

Foi procedido o cálculo do alfa de cronbach, para verificar o nível de confiabilidade e consistência interna do questionário, por ser este considerado mais útil para escalas de itens múltiplos no nível de intervalo de mensuração (COOPER; SCHINDLER, 2003). O resultado indicou um $a=$ 0,852 , considerado bom, uma vez que se situa acima dos níveis de $0,60 / 0,70$, considerados os limites inferiores de aceitabilidade (HAIR et. al., 2005).

O questionário solicitou aos respondentes que classificassem em uma escala Likert, variando de "1 - muito baixa" a "5 - muito alta", a frequência de obtenção de informações estratégicas úteis acerca de 19 aspectos do ambiente adaptados de Beal (2000) e a necessidade de obtenção de mais informações sobre cada um dos aspectos ambientais. Os dados de caracterização das empresas foram levantados em termos de número de empregados, receita bruta anual, tempo de existência em anos, setor de atuação e grau de parentesco entre os sócios. Os dados dos respondentes foram levantados em termos de gênero, grau de instrução e cargo que ocupa na empresa.

Para a análise dos dados, utilizou-se a estatística descritiva, por meio de cálculo de médias, desvio padrão, contagem de frequência e cálculos percentuais e Análise de Variância (ANOVA), para verificar as diferenças entre médias entre os agrupamentos de empresas conforme o porte e a idade. Buscou-se identificar os tipos de informação com maior e menor frequência de monitoramento, as principais necessidades de obtenção de informações pelas empresas pesquisadas e as diferenças de médias entre empresas maiores e menores e, ainda, empresas mais velhas e mais novas.

Para a ANOVA, foi calculado o índice $F$ para a variância entre e dentro dos grupos para cada uma das 19 variáveis dependentes em relação a 3 variáveis de grupo: idade, porte medido por número de empregados e porte medido pela receita bruta anual. Para as variáveis dependentes, que apresentaram índices $F$ com significância estatística, foram realizados testes post hoc de Scheffé, para identificação das diferenças nos níveis de grupos. A análise e tratamento dos dados foram realizados, utilizando-se o SPSS (Statistical Package for the Social Science), versão 13.0 .

\section{Resultados e discussões}


Os resultados estão estruturados de acordo com a caracterização das empresas investigadas, com os dados descritivos do monitoramento em toda a amostra e com as diferenças de monitoramento com base na idade e porte das empresas.

\subsection{Caracterização das empresas pesquisadas}

As empresas pesquisadas foram caracterizadas em relação ao setor de atuação, ao porte (classificado segundo o número de funcionários e receita bruta), ao tempo de existência, à existência de parentesco entre sócios e/ou funcionários e ao cargo ocupado pelo respondente da pesquisa.

No que se refere ao setor de atividade, 39,7\% das empresas pesquisadas atuam no setor industrial, $31,5 \%$ no setor comercial e $28,8 \%$ no setor de serviços. Quanto ao número de empregados das empresas pesquisadas, 51,3\% das empresas possuem até 19 empregados.

Seguindo a classificação de porte do Instituto Brasileiro de Geografia e Estatística (IBGE), verificou-se na amostra pesquisada, que $47 \%$ das empresas pesquisadas são pequenas, $36 \%$ são micro, $11,5 \%$ são de médio porte e $5,5 \%$ das empresas pesquisadas podem ser classificadas como de grande porte. Em relação ao faturamento, 62,9\% das 178 empresas, que responderam a este quesito, indicaram ter receita bruta de até $\mathrm{R} \$ 1.200 .000,00$ (um milhão e duzentos mil reais) anuais, $21,3 \%$ entre $R \$ 1.200 .000,00$ e $10.000 .000,00$ (dez milhões de reais) anuais e $15,7 \%$ acima de $\mathrm{R} \$ 10.000 .000,00$ (dez milhões de reais) anuais.

A TAB. 1, a seguir, apresenta dados do cruzamento entre as variáveis "receita bruta anual" e "número de empregados".

TABELA 1 - Cruzamento entre receita bruta anual e número de empregados

\begin{tabular}{|c|c|c|c|c|c|c|c|}
\hline \multirow[t]{2}{*}{ Receita bruta anual } & \multicolumn{6}{|c|}{ Número de empregados } & \multirow[b]{2}{*}{$\begin{array}{l}\text { Total de } \\
\text { Casos }\end{array}$} \\
\hline & Até 9 & $10-19$ & $20-49$ & $50-99$ & $\begin{array}{l}100- \\
499\end{array}$ & $\begin{array}{l}500 \text { ou } \\
\text { mais }\end{array}$ & \\
\hline Até 120.000,00 & 25 & 11 & - & - & - & - & 36 \\
\hline $\begin{array}{l}\text { De } 120.000,01 \text { até } \\
500.000,00\end{array}$ & 20 & 13 & 8 & 1 & - & - & 42 \\
\hline $\begin{array}{l}\text { De } 500.000,01 \text { até } \\
1.200 .000,00\end{array}$ & 6 & 9 & 10 & 10 & - & - & 35 \\
\hline $\begin{array}{l}\text { De 1.200.000,01 até } \\
10.000 .000,00\end{array}$ & - & 5 & 18 & 14 & 1 & - & 38 \\
\hline $\begin{array}{l}\text { De 10.000.000,01 até } \\
50.000 .000,00\end{array}$ & - & 2 & 2 & 6 & 13 & 1 & 24 \\
\hline Acima de $50.000 .000,00$ & - & - & - & - & - & 3 & 4 \\
\hline Total de Casos & 51 & 40 & 38 & 31 & 14 & 4 & 178 \\
\hline
\end{tabular}

Fonte: Dados da pesquisa. 
Os dados da TAB. 1 indicam que as empresas menores, de acordo com o indicador número de funcionários, são as que apresentam, também, menor receita bruta. Dentre as 129 empresas com até 49 funcionários, 102 faturam até $R \$ 1,2$ milhão ao ano e apenas 27 passam deste valor. Já dentre as 31 empresas que possuem de 50 até 99 funcionários, apenas 11 faturam até $R \$ 1,2$ milhão ao ano e 20 passam deste valor. Isto mostra uma forte associação entre número de funcionários e faturamento, indicando que apenas um dos indicadores pode ser representativo do porte em pequenas empresas.

A TAB. 2, a seguir, apresenta os resultados do cruzamento entre o tempo de existência da empresa e a receita bruta anual.

TABELA 2 - Cruzamento entre receita bruta anual e tempo de existência da Empresas

\begin{tabular}{|c|c|c|c|c|c|c|c|}
\hline \multirow{2}{*}{$\begin{array}{l}\text { Receita } \\
\text { anual }\end{array}$} & \multicolumn{6}{|c|}{ Tempo de existência da empresa } & \multirow{2}{*}{$\begin{array}{c}\text { Total de } \\
\text { casos }\end{array}$} \\
\hline & $\begin{array}{l}\text { Menos } \\
\text { de } 1 \text { ano }\end{array}$ & $\begin{array}{l}\text { De } 1 \text { a } 2 \\
\text { anos }\end{array}$ & $\begin{array}{l}\text { De } 3 \text { a } 5 \\
\text { anos }\end{array}$ & $\begin{array}{c}\text { De seis a } \\
10 \text { anos }\end{array}$ & $\begin{array}{l}\text { De } 11 \text { a } \\
15 \text { anos }\end{array}$ & $\begin{array}{l}\text { Mais de } \\
15 \text { anos }\end{array}$ & \\
\hline Até $120.000,00$ & 3 & 5 & 6 & 10 & 9 & 3 & 36 \\
\hline $\begin{array}{l}\text { De 120.000,01 até } \\
500.000,00\end{array}$ & 1 & 6 & 3 & 12 & 6 & 14 & 42 \\
\hline $\begin{array}{l}\text { De 500.000,01 até } \\
1.200 .000,00\end{array}$ & 1 & - & 3 & 7 & 10 & 14 & 36 \\
\hline $\begin{array}{l}\text { De } 1.200 .000,01 \\
\text { até } 10.000 .000,00\end{array}$ & 1 & 1 & 1 & 3 & 15 & 17 & 38 \\
\hline $\begin{array}{l}\text { De } \quad 10.000 .000,01 \\
\text { até } 50.000 .000,00\end{array}$ & 1 & - & - & 3 & 5 & 15 & 24 \\
\hline $\begin{array}{ll}\text { Acima } & \text { de } \\
50.000 .000,00 & \end{array}$ & - & - & - & - & - & 3 & 4 \\
\hline Total de Casos & 7 & 12 & 13 & 35 & 45 & 66 & 178 \\
\hline
\end{tabular}

Fonte: Dados da pesquisa.

A TAB. 2 indica que a variável idade não deve possuir associação forte com o porte em termos de receita bruta anual. Embora as empresas pesquisadas mais novas apresentem faturamento menor, entre as mais velhas encontram-se empresas com os mais variados níveis de receita. Das 67 empresas com até 10 anos de idade, 57 faturam até $R \$ 1,2$ milhão por ano e apenas 10 ultrapassam este valor. Já dentre as 106 empresas com mais de 10 anos de idade, há uma distribuição equilibrada com 56 faturando anualmente até $\mathrm{R} \$ 1,2$ milhão e 50 empresas ultrapassando este valor.

A pesquisa também indicou que em $68,4 \%$, das empresas pesquisadas, existe grau de parentesco entre os sócios e os funcionários, o que caracteriza essas organizações como familiares. Bernhoeft (1989) define uma empresa familiar como aquela que tem sua origem e sua história vinculados a uma família ou que mantém membros da família na administração dos negócios. A existência de membros da família em empresas de pequeno porte é muito comum. Um cruzamento entre número de empregados e o grau de parentesco demonstrou que das empresas caracterizadas como familiares $(n=128), 43,72 \%$ possuem até 
19 empregados, $25 \%$ de 20 a 49 empregados e $23,44 \%$ de 50 a 99 empregados, o que indica que a maioria das empresas familiares pesquisadas pode ser considerada de pequeno porte, tomando como referência o número de empregados. Como uma parte das empresas pesquisadas $(36,9 \%)$ possui mais de 15 anos de existência, a sucessão familiar começa a se tornar uma questão importante para essas organizações. Em relação aos respondentes do questionário, 43,0\% são sócios-proprietários, com atividades de gestão na empresa e $42,5 \%$ são diretores ou gerentes não proprietários.

\subsection{Frequência de monitoramento das informações estratégicas}

A frequência de monitoramento das informações sobre os aspectos do ambiente externo foi obtida através da utilização de uma escala pelos respondentes, que indicavam o grau de frequência de obtenção de informações para 19 aspectos externos. A escala variou de 1 (frequência muito baixa) a 5 (frequência muito alta). Além da frequência de monitoramento para cada aspecto, as empresas foram questionadas se havia necessidade de obter mais informações úteis sobre o respectivo aspecto para a tomada de decisões gerenciais. A TAB. 3 apresenta os aspectos em ordem decrescente da média obtida, além do desvio padrão e do percentual de empresas que responderam sim ou não para a necessidade de mais informações sobre cada aspecto ambiental.

TABELA 3 - Frequência do Monitoramento do Ambiente Externo

\begin{tabular}{|c|c|c|c|c|}
\hline \multirow{2}{*}{ Aspecto do Ambiente Externo } & \multicolumn{2}{|c|}{ Frequência } & \multicolumn{2}{|c|}{$\begin{array}{l}\text { Há necessidade de } \\
\text { mais informações? }\end{array}$} \\
\hline & Média & $\begin{array}{l}\text { Desvio } \\
\text { Padrão }\end{array}$ & Sim & Não \\
\hline Necessidades dos clientes & 4,12 & 0,88 & $81,8 \%$ & $18,2 \%$ \\
\hline Preços e prazos praticados pelos fornecedores & 3,81 & 1,11 & $62,7 \%$ & $37,3 \%$ \\
\hline Hábito de compras dos clientes & 3,64 & 1,03 & $75,3 \%$ & $24,7 \%$ \\
\hline Leis e normas que regulam o setor & 3,53 & 1,06 & $75,1 \%$ & $24,9 \%$ \\
\hline Fornecedores - inovação em insumos/serviços & 3,46 & 1,10 & $66,3 \%$ & $33,7 \%$ \\
\hline Preços praticados pelos concorrentes & 3,44 & 1,18 & $60,7 \%$ & $39,3 \%$ \\
\hline $\begin{array}{l}\text { Surgimento de inovações tecnologias aplicadas aos } \\
\text { produtos, serviços ou processos da empresa }\end{array}$ & 3,38 & 0,94 & $76,8 \%$ & $23,2 \%$ \\
\hline $\begin{array}{l}\text { Utilização que os clientes fazem dos produtos e } \\
\text { serviços }\end{array}$ & 3,37 & 1,12 & $58,8 \%$ & $41,2 \%$ \\
\hline $\begin{array}{l}\text { Condições gerais da economia (EX: taxas de juros, } \\
\text { inflação, câmbio, PIB) }\end{array}$ & 3,37 & 1,05 & $57,6 \%$ & $42,4 \%$ \\
\hline Identificação de novos fornecedores & 3,36 & 1,08 & $70,9 \%$ & $29,1 \%$ \\
\hline $\begin{array}{l}\text { Perfil dos clientes (socioeconômico, distribuição } \\
\text { geográfica) }\end{array}$ & 3,32 & 1,16 & $72,8 \%$ & $27,2 \%$ \\
\hline $\begin{array}{l}\text { Mudanças nas tendências do mercado de atuação } \\
\text { (crescimento, declínio, novos segmentos de clientes, } \\
\text { novos usos para o produto, etc) }\end{array}$ & 3,27 & 1,06 & $77,5 \%$ & $22,5 \%$ \\
\hline Introdução de novos produtos pelos concorrentes & 3,06 & 1,22 & $63,1 \%$ & $36,9 \%$ \\
\hline Mudanças nos produtos dos concorrentes & 2,97 & 1,17 & $56,4 \%$ & $43,6 \%$ \\
\hline Práticas de bancos e financiadores & 2,84 & 1,20 & $45,7 \%$ & $54,3 \%$ \\
\hline
\end{tabular}




\begin{tabular}{l|c|c|c|c}
\hline Condições socioculturais da sociedade & 2,84 & 1,15 & $54,5 \%$ & $45,5 \%$ \\
\hline Mudanças no Marketing dos concorrentes & 2,66 & 1,15 & $47,8 \%$ & $52,2 \%$ \\
\hline Condições demográficas da população & 2,64 & 1,28 & $52,0 \%$ & $48,0 \%$ \\
\hline Custos e resultados financeiros dos concorrentes & 1,89 & 1,04 & $42,0 \%$ & $58,0 \%$ \\
\hline
\end{tabular}

Fonte: Dados da pesquisa.

Pode-se observar que entre os aspectos com maior média de monitoramento estão os relacionados com a categoria clientes, que possui a única variável com média acima de 4,0 e 2 variáveis dentre as $3 \mathrm{com}$ maior média. Esse resultado está alinhado com outros realizados na área, em que o mercado de atuação e clientes figuram como os aspectos mais monitorados em pequenas empresas (SMELTZER et al.; 1988; JOHNSON; KUEHN, 1987). Em seguida aos clientes, estão os aspectos ligados aos fornecedores e normas do setor.

Tomando a mediana de 3,36, percebe-se que no grupo de maior média, predominam aspectos do ambiente de tarefa com apenas a variável "condições gerais da economia" fazendo parte desse grupo. Os demais aspectos do macroambiente, apresentaram médias que ficaram abaixo da mediana da amostra. Essa menor atenção com o macroambiente também foi identificada no estudo de Mohan-Neill (1995) e Johnson e Kuehn (1987). No entanto, o trabalho de Beal (2000), ao separar as empresa por desempenho, encontrou resultados diversos para aqueles de performance superior, ou seja, monitoraram tanto aspectos do ambiente de tarefa quanto do macroambiente.

Poderia-se supor que, quanto mais um aspecto é monitorado, mais informações se obtêm sobre ele e, consequentemente, menor torna-se a necessidade de obter-se mais dados. Isto não é verificado na pesquisa, pois os aspectos mais monitorados também estão entre aqueles que as empresas indicaram necessitar de mais informações. Esta constatação pode encobrir atividades de monitoramento pouco eficazes e estruturadas que, mesmo com alta frequência de busca, não proporcionam as informações desejadas.

Dentre os aspectos com menor frequência de monitoramento, ganham destaque aqueles relacionados à categoria concorrentes, que possui a única variável com média inferior a 2 e duas variáveis dentre as três com menor média. Considerando as variáveis com média inferior a mediana, pode-se constatar que a categoria concorrentes possui 4 variáveis nesse grupo, com apenas os "preços praticados pelos concorrentes" com média superior à mediana. A presença dos concorrentes entre os fatores menos monitorados corrobora pesquisas no exterior (FANN; SMELTZER, 1989 e GROOM; DAVID, 2001) e no Brasil (FIDELIS; CENDON, 2002 e ALMEIDA, 1997), que identificaram que as pequenas e médias empresas pouco valorizam informações sobre eles ou o fazem de forma esporádica e pouco frequente.

Além dos concorrentes, condições demográficas da população, prática dos bancos e condições socioculturais, situaram-se entre as menores médias do estudo. Inversamente aos aspectos mais 
monitorados, os menos monitorados são aspectos que um menor número de empresas demonstrou necessidade de obter mais informações.

\subsection{Influência do porte e da idade no monitoramento em pequenas empresas}

Para avaliar as diferenças de monitoramento, com base na idade e no porte, foram formados grupos de empresas, conforme a classificação de acordo com o tempo de existência em anos, número de funcionários e receita bruta anual conforme a TAB. 4.

TABELA 4 - Agrupamentos por porte e idade

\begin{tabular}{|c|c|c|c|c|c|}
\hline $\begin{array}{l}\text { Número de } \\
\text { funcionários }\end{array}$ & $N$ & $\begin{array}{l}\text { Receita bruta anual (em } \\
\text { R\$) }\end{array}$ & $n$ & $\begin{array}{l}\text { ldade (em } \\
\text { anos) }\end{array}$ & $n$ \\
\hline Até 19 & 96 & Até 1,2 milhão & 112 & Até 2 anos & 20 \\
\hline De 20 a 99 & 72 & De 1,2 a 10 milhões & 38 & De 3 a 5 anos & 14 \\
\hline Mais de 100 & 19 & Mais de 10 milhões & 28 & De 6 a 10 anos & 39 \\
\hline & & & & $\begin{array}{l}\text { Mais de } 10 \\
\text { anos }\end{array}$ & 114 \\
\hline Não informado & 1 & & 10 & & 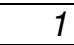 \\
\hline TOTAL & 188 & & 188 & & 188 \\
\hline
\end{tabular}

Fonte: Dados da pesquisa.

Para cada uma das faixas de porte e idade, foram calculadas as diferenças de médias pela técnica ANOVA para os dezenove aspectos do ambiente externo investigados, sendo apresentadas e discutidas as variáveis que indicaram diferenças estatisticamente significantes ao nível de 0,05 e 0,10.

Para diferenças de porte, de acordo com número de funcionários, foi identificada apenas a variável "Mudanças nas tendências do mercado de atuação", conforme TAB. 5. No teste Scheffé (Tabela 6), as empresas menores com até 19 (média 3,26) e entre 10 e 99 funcionários (média $3,10)$ mostraram médias significativamente inferiores àquelas com mais de 100 empregados (média 4,05). Embora diferentes entre si ao nível de 0,10 , as empresas com até 19 e entre 20 e 99 funcionários apresentaram médias bastante próximas entre si.

TABELA 5 -nANOVA das diferenças significativas com base no porte (empregados)

\begin{tabular}{llrrrrr}
\hline \multicolumn{1}{c}{ Variável dependente } & & $\begin{array}{c}\text { Soma de } \\
\text { quadrados }\end{array}$ & df & $\begin{array}{c}\text { Média ao } \\
\text { quadrado }\end{array}$ & F & Sig. \\
\hline \multirow{2}{*}{$\begin{array}{llrl}\text { Mudanças nas tendências do } \\
\text { mercado de atuação }\end{array}$} & $\begin{array}{l}\text { Entre grupos } \\
\text { Dentro dos }\end{array}$ & 13,667 & 2 & 6,834 & 6,436 & 0,00 \\
& grupos & 191,120 & 180 & 1,062 & & \\
& Total & 204,787 & 182 & & & \\
\hline
\end{tabular}

Fonte: Dados da pesquisa. 
TABELA 6 - Teste Scheffé para diferenças significativas em médias de grupos com base no porte (empregados)

\begin{tabular}{lccrc}
\hline \multicolumn{1}{c}{ Variável dependente } & \multicolumn{2}{c}{$\begin{array}{c}\text { Diferenças de média por } \\
\text { Porte (empregados) }\end{array}$} & $\begin{array}{c}\text { Diferença } \\
\text { média }\end{array}$ & Sig. \\
\hline $\begin{array}{l}\text { Mudanças nas tendências do } \\
\text { mercado de atuação }\end{array}$ & Até 19 & De 20 a 99 & 0,155 & 0,63 \\
& & Mais de 100 & $-0,797$ & 0,01 \\
& De 20 a 99 & Mais de 100 & $-0,953$ & 0,00 \\
\hline
\end{tabular}

Fonte: Dados da pesquisa.

Para diferenças de porte, de acordo com a receita bruta anual, foram identificadas diferenças significativas em um número maior de variáveis do que o porte por número de funcionários (TAB. 7). Em comum, a variável mudanças nas tendências do mercado de atuação, que demonstrou significância em ambas as medidas.

TABELA 7 - ANOVA das diferenças significativas com base no porte (receita bruta anual)

\begin{tabular}{|c|c|c|c|c|c|c|}
\hline Variável dependente & & $\begin{array}{c}\text { Soma de } \\
\text { quadrados }\end{array}$ & df & $\begin{array}{l}\text { Média ao } \\
\text { quadrado }\end{array}$ & $\mathbf{F}$ & Sig. \\
\hline \multirow{3}{*}{$\begin{array}{l}\text { Mudanças nas tendências } \\
\text { do mercado de atuação }\end{array}$} & Entre grupos & 8,003 & 2 & 4,001 & 3,710 & 0,03 \\
\hline & Dentro dos grupos & 184,457 & 171 & 1,079 & & \\
\hline & Total & 192,460 & 173 & & & \\
\hline \multirow{3}{*}{$\begin{array}{l}\text { Práticas de bancos e } \\
\text { financiadores }\end{array}$} & Entre grupos & 12,197 & 2 & 6,098 & 4,485 & 0,01 \\
\hline & Dentro dos & 232,493 & 171 & 1,360 & & \\
\hline & Total & 244,690 & 173 & & & \\
\hline \multirow{3}{*}{$\begin{array}{l}\text { Leis e normas que regulam } \\
\text { o setor }\end{array}$} & Entre grupos & 6,465 & 2 & 3,233 & 2,865 & 0,06 \\
\hline & Dentro dos grupos & 192,943 & 171 & 1,128 & & \\
\hline & Total & 199,408 & 173 & & & \\
\hline
\end{tabular}

Fonte: Dados da pesquisa.

O teste Scheffé (TAB. 8), demonstra que nas três variáveis, as empresas com receita superior a $R \$ 10$ milhões obtiveram médias estatisticamente diferentes, tanto em relação aquelas com receita até $\mathrm{R} \$$ 1,2 milhão como para aquelas com receita entre $R \$ 1,2$ e 10 milhões. Entre os dois estratos menores de empresas (Até 1,2 e de 1,2 a 10 milhões) não foram verificadas diferenças significativas nas médias dos grupos.

O grupo de empresas com receita superior a $\mathrm{R} \$ 10$ milhões obteve as médias de frequência de monitoramento de 3,79 para a variável "Mudanças nas tendências do mercado de atuação", 3,46 para "Práticas 
de bancos e financiadores" e 3,96 para "Leis e normas que regulam o setor".

Os dados conjuntos das diferenças no monitoramento quanto ao porte, indicam que há aspectos ambientais que podem se tornar mais influentes na medida em que as empresas crescem. Bancos e financiadores podem se tornar mais relevantes, quando as empresas crescem e aumentam o volume de recursos que precisam administrar. No entanto, tais diferenças podem ser relativas à falta de atenção dos administradores das empresas menores ou do foco no curto prazo das decisões, o que pode explicar uma menor atenção para com as mudanças em tendências de mercados.

TABELA 8 - Teste Scheffe para diferenças significativas em médias de grupos com base no porte (receita)

\begin{tabular}{lrrrr}
\hline \multicolumn{1}{c}{ Variável dependente } & Diferenças de média por Porte (receita) & \multicolumn{2}{c}{$\begin{array}{l}\text { Diferença } \\
\text { média }\end{array}$} & Sig. \\
\hline $\begin{array}{l}\text { Mudanças nas tendências do } \\
\text { mercado de atuação }\end{array}$ & Até 1,2 milhão Mais de 10 milhões & $-0,566$ & 0,04 \\
\hline $\begin{array}{l}\text { Práticas de bancos e } \\
\text { financiadores }\end{array}$ & De 1,2 até 10 milhões Mais de 10 milhões & $-0,624$ & 0,06 \\
\hline Leis e normas que regulam o & Até 1,2 milhão Mais de 10 milhões & $-0,733$ & 0,01 \\
setor & De 1,2 até 10 milhões Mais de 10 milhões & $-0,675$ & 0,07 \\
\hline
\end{tabular}

Fonte: Dados da pesquisa.

A idade foi o fator que apresentou um maior número de variáveis, com diferenças entre médias de monitoramento, todas com significância no nível de 0,05. A maior parte delas (4) refere-se à categoria concorrentes; e uma variável é relativa aos fornecedores; e nenhuma delas mostrou diferença estatística nos critérios de porte.A TAB. 9 apresenta os resultados do teste de análise de variância.

TABELA 9 - ANOVA das diferenças significativas de médias de monitoramento com base na idade

\begin{tabular}{|c|c|c|c|c|c|c|}
\hline Variável dependente & & $\begin{array}{c}\text { Soma de } \\
\text { quadrados }\end{array}$ & df & $\begin{array}{l}\text { Média ao } \\
\text { quadrado }\end{array}$ & $\mathbf{F}$ & Sig. \\
\hline \multirow{3}{*}{$\begin{array}{l}\text { Mudanças nos produtos dos } \\
\text { concorrentes }\end{array}$} & Entre grupos & 17,317 & 3 & 5,772 & 4,431 & 0,00 \\
\hline & Dentro dos grupos & 234,488 & 180 & 1,303 & & \\
\hline & Total & 251,804 & 183 & & & \\
\hline \multirow{3}{*}{$\begin{array}{l}\text { Mudanças no marketing dos } \\
\text { concorrentes }\end{array}$} & Entre grupos & 10,851 & 3 & 3,617 & 2,800 & 0,04 \\
\hline & Dentro dos grupos & 235,128 & 182 & 1,292 & & \\
\hline & Total & 245,978 & 185 & & & \\
\hline \multirow{3}{*}{$\begin{array}{l}\text { Introdução de novos produtos } \\
\text { pelos concorrentes }\end{array}$} & Entre grupos & 20,118 & 3 & 6,706 & 4,774 & 0,00 \\
\hline & Dentro dos grupos & 254,228 & 181 & 1,405 & & \\
\hline & Total & 274,346 & 184 & & & \\
\hline \multirow{2}{*}{$\begin{array}{l}\text { Custos e resultados financeiros } \\
\text { dos concorrentes }\end{array}$} & Entre grupos & 12,715 & 3 & 4,238 & 4,103 & 0,01 \\
\hline & Dentro dos grupos & 183,862 & 178 & 1,033 & & \\
\hline
\end{tabular}




\begin{tabular}{|c|c|c|c|c|c|c|}
\hline & Total & 196,577 & 181 & & & \\
\hline \multirow{3}{*}{$\begin{array}{l}\text { Fornecedores - inovação em } \\
\text { insumos/serviços }\end{array}$} & Entre grupos & 10,954 & 3 & 3,651 & 3,106 & 0,03 \\
\hline & Dentro dos grupos & 210,401 & 179 & 1,175 & & \\
\hline & Total & 221,355 & 182 & & & \\
\hline
\end{tabular}

Fonte: Dados da pesquisa.

No teste Scheffé (TAB. 10), pode-se perceber que as diferenças estão em maior parte entre os grupos extremos de idade da pesquisa. As empresas com até dois anos, apresentaram médias superiores de frequência de monitoramento dos concorrentes do que as mais velhas, em especial as com mais de 10 anos de existência. Esse dado surpreendente parece indicar que as empresas mais novas estão mais preocupadas com a concorrência do que suas congêneres mais velhas, o que diverge dos resultados obtidos por Mohan-Neiil (1995), que encontrou uma correlação positiva entre idade e o monitoramento da estratégia, das vendas e dos serviços concorrentes.

Em relação à inovação dos fornecedores, as empresas com mais de 10 anos obtiveram uma média de frequência de monitoramento superior estatisticamente as com até 2 anos de idade.

TABELA 10 - Teste Scheffe para diferenças significativas em médias de grupos com base na idade

\begin{tabular}{|c|c|c|c|c|}
\hline Variável dependente & Diferença & $\begin{array}{l}\text { s de média por } \\
\text { Idade }\end{array}$ & $\begin{array}{l}\text { Diferença } \\
\text { média }\end{array}$ & Sig. \\
\hline \multirow{2}{*}{$\begin{array}{l}\text { Mudanças nos produtos dos } \\
\text { concorrentes }\end{array}$} & \multirow{2}{*}{ Até 2 anos } & 6 a 10 anos & 0,853 & 0,07 \\
\hline & & Mais de 10 anos & 0,996 & 0,01 \\
\hline $\begin{array}{l}\text { Mudanças no marketing dos } \\
\text { concorrentes }\end{array}$ & Até 2 anos & Mais de 10 anos & 0,789 & 0,05 \\
\hline $\begin{array}{l}\text { Introdução de novos produtos } \\
\text { pelos concorrentes }\end{array}$ & Até 2 anos & Mais de 10 anos & 0,977 & 0,01 \\
\hline $\begin{array}{l}\text { Custos e resultados } \\
\text { financeiros dos concorrentes }\end{array}$ & 3 a 5 anos & $\mathrm{Ma}$ & 0,857 & 0,03 \\
\hline $\begin{array}{l}\text { Fornecedores - inovação em } \\
\text { insumos/serviços }\end{array}$ & Até 2 anos & Mais de 10 anos & $-0,760$ & 0,05 \\
\hline
\end{tabular}

Fonte: Dados da pesquisa.

\section{Considerações finais}

As informações, atualmente, têm um valor estratégico para as organizações. Sua utilização de forma eficiente e eficaz pode representar um diferencial importante em relação aos concorrentes, para a sobrevivência e o crescimento organizacional.

Esta pesquisa mostrou que as pequenas e médias empresas da região da grande Florianópolis, executam atividades de monitoramento do ambiente externo e não se caracterizam como sistemas fechados. No entanto, alguns aspectos externos são mais privilegiados do que outros no monitoramento. Clientes e fornecedores são fatores monitorados com maior frequência do que os concorrentes e as condições demográficas e socioculturais da sociedade. 
Os resultados indicam que o ambiente de tarefa parece predominar no esforço de monitoramento das pequenas empresas, com pouca atenção sendo dada para aspectos do macroambiente. Assim como em outros estudos realizados no Brasil e no exterior, os concorrentes continuam sendo negligenciados em suas práticas. As empresas da pesquisa parecem reduzir a dimensão dos correntes restringindo-as aos preços praticados, excluindo, assim, inovações, custos e mudanças mercadológicas por eles provocadas.

Outra contribuição que se pode destacar, neste estudo, está na busca de diferenças nas atividades de monitoramento entre empresas de diferentes portes e idades. Os resultados sugerem que o fator idade pode ser mais influente do que o porte, nas diferenças de monitoramento entre as pequenas e médias empresas tomadas em conjunto.

Dentre as limitações deste estudo, destacam-se os variados tamanhos dos grupos que, se fossem semelhantes, permitiram identificar com mais precisão as diferenças entre as variáveis do monitoramento. Amostras maiores que as aqui obtidas também poderiam reforçar os resultados obtidos e torná-los mais relevantes.

Os resultados obtidos permitem ponderar pela validade e continuidade de se pesquisar o tema proposto. A obtenção de respostas, levando em conta os diferentes setores de atuação, pode reforçar e delimitar os resultados aqui alcançados. O conteúdo dos resultados obtidos sugerem pesquisas acerca do uso e razões da preferência/negligência de certos tipos de informação no monitoramento. Igualmente, estudos que levem em conta as diferenças no uso de fontes de informação podem contribuir para o tema.

Por fim, sugere-se o uso de metodologias qualitativas, que podem oportunizar a obtenção de dados no contexto e na realidade social em que o monitoramento ocorre, captando aspectos manifestos e não manifestos sobre o fenômeno monitoramento ambiental, na pequena e média empresa.

\section{Referências}

AGUILAR, F. J. Scanning the business environment. New York: MacMillan, 1967.

ALMEIDA, M. I. R. Será possível as pequenas e médias empresas crescerem sem informações do ambiente? (1997). In: ENCONTRO DA ASSOCIAÇÃO NACIONAL DOS PROGRAMAS DE PÓS-GRADUAÇÃO EM ADMINISTRAÇÃO, 21., 1997, Rio das Pedras/RJ. Anais... Rio das Pedras: [s.n.], 1997.

ANALOUI, F.; KARAMI, A.. How chief executives' perception of the environment impacts on company performance. The Journal of Management Development, v. 21, n. 4, p. 290-305, 2002. 
BARBOSA, R. R. Uso de fontes de informação para a inteligência competitiva: um estudo da influência do porte das empresas sobre o comportamento informacional. Encontros Bibli, n. esp., 1ํ sem., p. 91-102, 2006.

BEAL, R. M. Competing effectively: Environmental scanning, competitive strategy, and organizational performance in small manufacturing firms. Journal of Small Business Management, v. 38, n. 1, p. 27-47, jan. 2000.

BERNHOERFT, R. Sucessão familiar: sucessão profissionalizada ou sobrevivência comprometida. 2. ed. São Paulo: Nobel, 1989.

BRUSCH, C. Marketplace information scanning activities of new manufacturing ventures. Journal of Small Business Management, v. 30, $\mathrm{n}$. 4, p. 41-51, 1992.

BRYMAN, A. Research methods and organizational studies. London: Routledge, 1989.

CHEN, M-J.; HAMBRICK, D. C. Speed, stealth, and selective attack: how small firms differ from large firms in competitive behavior. Academy of Management Journal, v. 38, n. 2, p. 453-483, 1995.

$\mathrm{CHOO}, \mathrm{C}$. W. The art of scanning the environment. Bulletin of the American Society for Information Science, v. 25, n. 3, p. 21-24, Feb./Mar. 1999.

COOPER, D. R.; SCHINDLER, P. S. Métodos de pesquisa em administração. 7. ed. Porto Alegre: Bookman, 2003.

DILL, W. R. Environment as an influence on managerial autonomy. Administrative Science Quarterly, v. 20, n. 4, p. 613-629, 1958.

FANN, G. L.; SMELTZER, L. R. The use of information from and about competitors in small business management. Entrepreneurship Theory and Practice, v. 13, n. 4, p.35-46, Summer 1989.

FIDELIS, J. R. F.; CENDON, B. V. Inteligência empresarial no setor metal mecânico. In: WORKSHOP BRASILEIRO DE INTELIGÊNCIA COMPETITIVA E GESTÃO DO CONHECIMENTO, 3., 2002, São Paulo/SP. Anais... São Paulo: [s.n.], 2002.

GHOSHAL, S. Environmental scanning in Korean firms: organizational isomorphism in action. Journal of International Business Studies, v. 19, n. 1, p. 69-86, 1988.

GOLDE, R. A. Practical planning for small business. Harvard Business Review, v. 42, n. 3, p. 147-161, 1964.

GROOM, J. R.; DAVID, F. R. Competitive intelligence activity among small firms. S.A.M. Advanced Management Journal, v. 66, n. 1, p. 12-20, Winter 2001.

HAIR, J. F. et al. Análise multivariada de dados. 5. ed. Porto Alegre: Bookman, 2005.

HALL, R. H. Organizações: estrutura e processos. 3. ed. Rio de Janeiro: Prentice-Hall do Brasil, 1984. 
HAMBRICK, D. C. Specialization of environmental scanning activities among upper level executives. Journal of Management Studies, v. 18, n. 3, p. 299-330, 1981.

JOHNSON, J. L.; KUEHN, R. The small business owner/manager's search for external information. Journal of Small Business Management, v. 25, n. 3, p. 53-61, Jul. 1987.

KAGAN, A. et al. Information system usage within small business firms. Entrepreneurship Theory and Practice, v. 14, n. 3, p. 25-37, 1990.

LANG, J. R. et al. Small firm information seeking as a response to environmental threats and opportunities. Journal of Small Business Management, v. 35, n. 1, p. 11-23, Jan. 1997.

MOHAN-NEIIL, S. I. The influence of firm's age and size on its environmental scanning activities. Journal of Small Business Management, v. 3, n. 4, p. 10-21, 1995.

PEARCE II, J. A. et al. Environmental scanning for small and growing firms. Journal of Small Business Management, v. 20, n. 3, p. 27-34, July 1982.

PINEDA, R. C. et al. An investigation of factors affecting the informationsearch activities of small business managers. Journal of Small Business Management, v. 36, n. 1, p. 60-71, 1998.

SEBRAE. Fatores condicionantes e taxa de mortalidade de empresas no Brasil. Brasília: SEBRAE, 2004.

SMELTZER, L. R. et al. Environmental Scanning Practices in Small Business. Journal of Small Business Management, v. 26, n. 3, p. 55-62, Jul. 1988.

STRANDHOLM, K.; KUMAR, K. Differences in environmental scanning activities between large and small organizations: the advantage of size. Journal of American Academy of Business, v. 3, n. 1/2, p. 416-421, 2003.

SUBRAMANIAN, R.; FERNANDES, N.; HARPER, E. Environmental scanning in U.S. companies: their nature and their relationship to performance. Management International Review; v. 33, n. 3, p. 271- 286, 1993. 